\title{
Rate adaptive pacing in people with chronic heart failure increases peak heart rate but not peak exercise capacity: a systematic review
}

\author{
H. I. Clark ${ }^{1}$ (D) - M. J. Pearson ${ }^{1}$ (D) N N. A. Smart ${ }^{1}$ (D)
}

Accepted: 24 January 2022 / Published online: 9 February 2022

(c) The Author(s) 2022

\begin{abstract}
Rate adaptive cardiac pacing (RAP) allows increased heart rate (HR) in response to metabolic demand in people with implantable electronic cardiac devices (IECD). The aim of this work was to conduct a systematic review to determine if RAP increases peak exercise capacity (peak $\mathrm{VO}_{2}$ ) in line with peak HR in people with chronic heart failure. We conducted a systematic literature search from 1980, when IECD and RAP were first introduced, until 31 July 2021. Databases searched include PubMed, Medline, EMBASE, EBSCO, and the Clinical Trials Register. A comprehensive search of the literature produced a total of 246 possible studies; of these, 14 studies were included. Studies and subsequent analyses were segregated according to comparison, specifically standard RAP (RAPON) vs fixed rate pacing (RAPOFF), and tailored RAP (TLD RAPON) vs standard RAP (RAPON). Pooled analyses were conducted for peak $\mathrm{VO}_{2}$ and peak HR for RAPON vs RAPOFF. Peak HR significantly increased by $15 \mathrm{bpm}$ with RAPON compared to RAPOFF (95\%CI, 7.98-21.97, $P<0.0001$ ). There was no significant difference between pacing mode for peak $\mathrm{VO}_{2} 0.45 \mathrm{ml} \mathrm{kg}^{-1} \mathrm{~min}^{-1}(95 \% \mathrm{CI},-0.55-1.47, P=0.38)$. This systematic review revealed RAP increased peak HR in people with CHF; however, there was no concomitant improvement in peak $\mathrm{VO}_{2}$. Rather RAP may provide benefits at submaximal intensities by controlling the rise in HR to optimise cardiac output at lower workloads. HR may be an important outcome of CHF management, reflecting myocardial efficiency.
\end{abstract}

Keywords Chronic heart failure $\cdot$ Chronotropic incompetence $\cdot$ Rate adaptive pacing $\cdot$ Heart rate $\cdot$ Exercise capacity

\section{Introduction}

Chronic heart failure (CHF) induces change in the molecular architecture of the myocardium [1,2]. Consequently, contractility and synchronicity of systolic and diastolic function are compromised [2], posing significant problems when metabolic demand is increased. Optimal cardiac function during exercise is dependent on an ability to increase heart rate (HR) and contractility [2], to compensate for decreased filling time of the left ventricle, which ultimately reduces stroke volume [3, 4]. The relationship between HR, stroke volume, and cardiac contractility facilitating optimal cardiac

H. I. Clark

hclark9@myune.edu.au

M. J. Pearson

mpears28@une.edu.au

N. A. Smart

nsmart2@une.edu.au

1 School of Science \& Technology, Exercise \& Sports Science, University of New England, Armidale, NSW, Australia hemodynamics is known as the force frequency relationship (FFR), which is intrinsic to cardiomyocytes [5-7]. In people with CHF, stroke volume adaptations to increased work and compensatory HR increases are critical to maintain adequate cardiac output [2]. At least $30-50 \%$ of people with CHF experience an inability to increase their HR to meet metabolic demands, generally termed chronotropic incompetence (CI) [8-11]. Also, approximately $25-30 \%$ of people with $\mathrm{CHF}$ experience electromechanical dysfunction resulting in atrioventricular, inter-ventricular, or intra-ventricular dysynchrony [8, 12-14]. This undermines the FFR and compensatory mechanisms during exercise, thus contributing to exercise intolerance [15].

Improvements in survival with optimal treatment in CHF have not been matched with improvements in health related quality of life (HRQoL) and exercise intolerance [9]. People with CHF incur persistent symptoms of shortness of breath, fatigue, and reduced functional capacity that may be associated with a blunted HR response to increased metabolic demand [11, 15]. Implantable electronic cardiac devices (IECD) have become a critical component of CHF 
management [16]. Rate adaptive cardiac pacing (RAP) is now available in all IECD's and was developed to assist in restoration of a physiological HR response to an increase in metabolic demand [10]. However, RAP is controversial and not well evidenced, demonstrating mixed results among other cardiac populations [17-20]. Excessive increases in HR may lead to ischemia, decreased LV diastolic filling time, and reduced contractility in CHF [21]. Therefore, change in HR may not be a benign variable, instead constituting an important physiological treatment target in the management of CHF. It has been proposed that RAP may produce iatrogenic worsening of myocardial failure [22]. Hence, there remains incongruence on the use and programming of RAP in IECDs.

As people with CHF, particularly when encumbered with CI, observe high mortality [11] as well as high morbidity rates and hospitalisation costs due to long term systemic adaptations and complex care [23], it is important to determine if RAP provides any benefit to people with CHF [16]. The purpose of this systematic review is to determine the efficacy of RAP in people with CHF, with respect to peak HR and exercise capacity.

\section{Methodology}

The search methodology was consistent with the PRISMA (Preferred Reporting Items for Systematic Reviews and Meta-Analyses) guidelines (Fig. 1). Reference lists of journal articles, meta-analyses, and systematic reviews were searched for additional articles. The clinical trial registry was also searched for unpublished results.

\section{Eligibility}

\section{Inclusion criteria}

Studies included were those which enrolled people with CHF with heart failure with reduced ejection fraction (HFrEF) and heart failure with preserved ejection fraction (HFpEF). Studies were required to compare standard rate adaptive pacing (RAPON) with fixed rate pacing (RAPOFF) (RAPON vs RAPOFF) or tailored RAP (TLD RAPON) with standard rate adaptive pacing (RAPON) (TLD RAPON vs RAPON). Segregating these studies from RAPON vs RAOFF studies is required as the purpose of RAP differs. Specifically, TLD RAPON vs RAPON studies aim to determine if tailoring RAP achieves better outcomes compared to conventional, non-specific RAP.

Included studies were randomised controls trials, observational or cross-over designs, or unpublished clinical trials. IECD could include CRT, PM, ICD, or a combination. All modes, sensors, and algorithms were included. Studies were required to assess exercise capacity via a cardiopulmonary exercise test or the 6 min walk test (6MWT). Studies had to be full text and in English.

\section{Exclusion criteria}

Studies were excluded if they were not specific to CHF or did not assess symptom limited exercise capacity. Abstracts and studies in a language other than English were excluded.

\section{Outcomes}

Primary outcome variables included peak HR, peak oxygen consumption (peak $\mathrm{VO}_{2}$ ), exercise time during maximal exercise test (ET), and 6MWT.

\section{Search strategy}

A systematic literature search was conducted from 1980 until January 30 2021. Databases searched include PubMed, Medline, EMBASE, EBSCO, and the Clinical Trials Register. To identify studies, the following MeSH terms were used; 'Rate Adaptive Pacing', 'Heart Failure', 'Humans', 'Heart Rate', 'Chronotropic Incompetence', 'Exercise Testing', 'Exercise Capacity', 'Exercise Intolerance', 'Cardiac Resynchronisation Therapy', 'Pacemaker Therapy', and 'Implantable Cardio-Defibrillator' (See Supplementary File).

\section{Data extraction and study selection}

One researcher (HC) extracted the data which was validated by a second researcher (MJP). Inconsistencies were reviewed by a third researcher (NAS) and resolved through consensus. This process was undertaken to ensure reliability and reduce the risk of bias. Article titles were screened for assessment of RAP. Abstracts and methodology were then reviewed according to the inclusion/exclusion criteria. All duplicates were removed.

\section{Calculating confidence intervals}

In this review, $95 \%$ and $84 \%$ confidence intervals (CONI) were calculated for each mean value where appropriate. The test of overlapping CONI when comparing an intervention to a control can be conducted to assess if there is a true statistical difference between the means. Mittal et al. [24] and Austin and Hux [25] suggest that if the CONI overlap at the $95 \%$ level, it does not necessarily refute the true statistical difference between the means. However if they do not overlap, then the statistical significance cannot be doubted. Alternatively, if one calculates the CONI at the $84 \%$ level, if the intervals do not overlap, the $P$ value associated with testing the difference between the 
Fig. 1 PRISMA statement

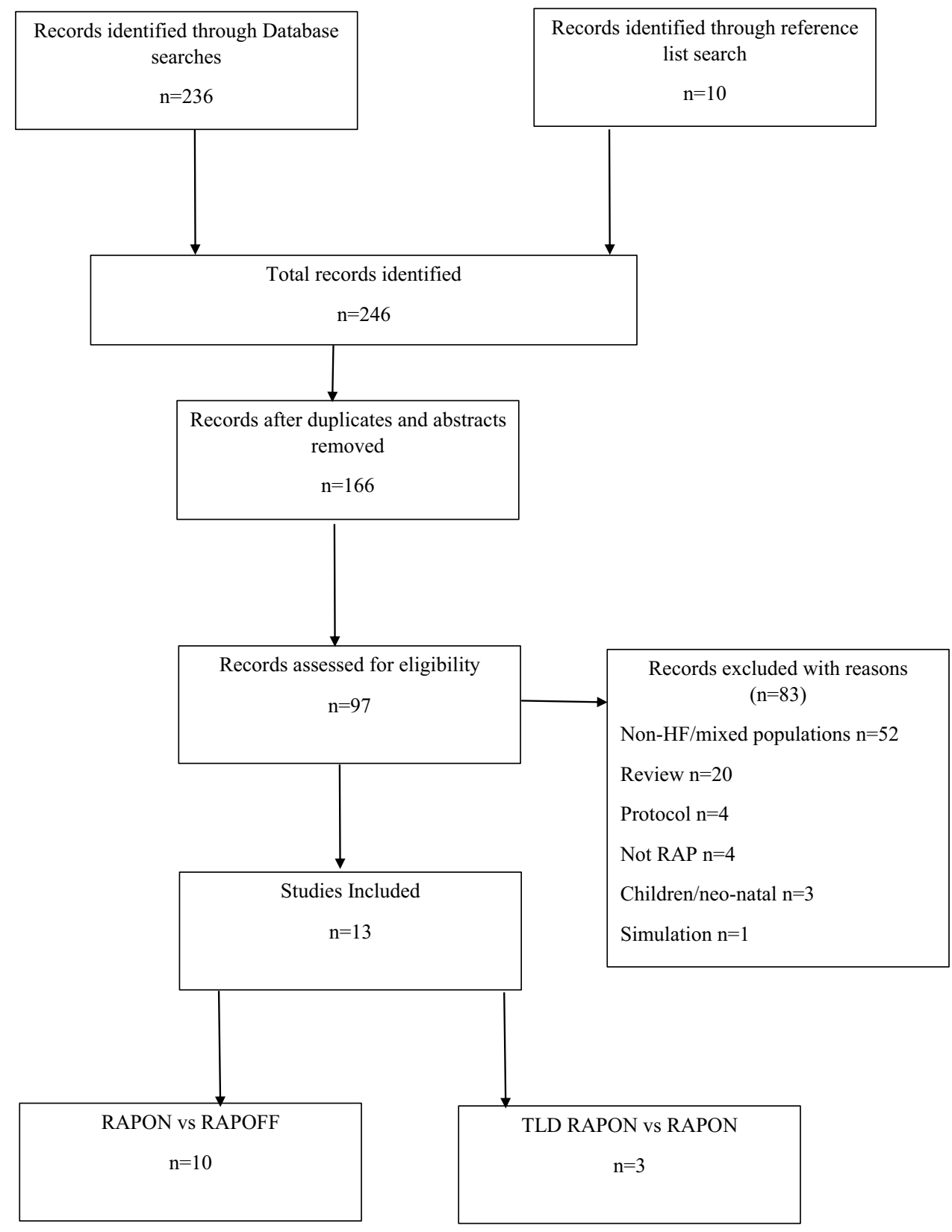

two means is approximately $95 \%(P=0.05)$ and is likely statistically different from one another [25, 26]. Furthermore, MacGregor-Fors and Payton [26] demonstrate that this test holds true for both asymmetric and symmetric CONI, reinforcing the robustness of this method.

To calculate each confidence interval, the standard deviation (SD) was multiplied by 1.96 (95\%CONI) and 1.37 ( $84 \%$ CONI). This value was then subtracted and added to the mean value to define the lower and upper limit of the CONI, respectively [26].

\section{Data pooling}

Data pooling occurred where appropriate, with a minimum of three studies reporting on the same outcome required. To pool data, all included studies followed the same study design, whether that be RCT or cross-over trials. When the standard error of the mean was present, the SD was calculated by multiplying the standard error of the mean by the square root of the number of participants [27]. Data evaluation was conducted using RevMan 5 (Review Manager 
Version 5.4.1, The Cochrane Collaboration, 2020). A random effects model was applied to account for the large variation in heart failure subtype and pacing modes, with a CONI of $95 \%$.

\section{Risk of bias}

Risk of bias was assessed according to the Revised Cochrane risk of bias tool for randomised trials (RoB2) with additional considerations for cross over trials [28]. The tool includes five domains, with an extra domain specific to crossover trial designs. Each question was answered with a yes (Y), probably yes (PY), not sure (NI), probably no (PN), or no (N). Each domain followed an algorithm according to the answers to the signalling questions. Domains could then be rated 'low risk', 'moderate risk', or 'high risk'. Studies were considered low, moderate or high risk according to the greatest number of domains with the same results.

\section{Results}

\section{Search}

A comprehensive search of the literature produced a total of 246 possible studies. Database searches collectively returned 236 hits, while 9 papers were identified through hand searching of reference lists and one study through the clinical trials database. A total of 80 duplicates were removed, and 166 items were screened by title. Of these, 97 studies were considered for further review that included screening of abstract, methodology, and results. Subsequently, 84 studies did not meet the inclusion criteria. A total of 13 studies are included in this review.

\section{Risk of bias}

Results for risk of bias are reported in the supplementary file. The risk of bias for randomised control trials [6, 12, 21,29 ] was low across all domains for all studies. The risk of bias for crossover trials [5, 22, 30-36] was low across all domains for all studies except Van Thielen et al. [5]. Van Thielen et al. [5] recorded high risk in domain 1 as the group allocation sequence was not randomised. Additionally, moderate risk of bias is reported for domain ' $S$ ' due to the inability to determine equal allocation of participants and the accounting for period effects in the analyses. However, as four out of the six domains reported low risk, this study was concluded to have a low overall risk of bias.

\section{Rate adaptive pacing vs fixed rate pacing}

\section{Study characteristics}

Ten studies compared standard RAP (RAPON) with fixed rate pacing (RAPOFF) (Table 1) [5, 12, 22, 29, 31-36]. Two studies were randomised control trials [12, 29], while the remaining eight were cross over trials. In particular, the study conducted by Kass and colleagues [31] was suspended due to poor recruitment. Therefore, the published protocol is cited here, while unpublished results are available at Clinicaltrials.gov (NTC00670111) and included in this review.

Across studies, devices included single chamber, dual chamber, and three chamber PM/ICD/CRT and included atrial, left uni-ventricular, and bi-ventricular (BiV) pacing. Modes included VVI, DDI, DDD, and AAI, with or without RAP (R) (Fig. 2: Schematic diagram of pacing modes; Table 2: Pacemaker Modes Terminology). RAP sensors included accelerometers [21, 30, 32, 33, 36] and blended minute ventilation and accelerometers [31]. Six studies did not specify the sensor used [5, 12, 22, 29, 34, 35].

\section{Participant characteristics}

An overview of study inclusion criteria and the variation in participant characteristics can be viewed in Fig. 3. The mean age of participants ranged from 54 [29] to 76 years [22]. A larger proportion of males was reported across studies (63.3 [32] to 90\% [33]). Ischemic aetiology was

Table 1 Pacemaker mode terminology

\begin{tabular}{lllll}
\hline \multicolumn{2}{l}{ The Heart Rhythm Society and British Pacing Electrophysiology Group guide to pacemaker modes of operation } \\
\hline$I$ & $I I$ & $I I I$ & $I V$ & $V$ \\
\hline Chamber(s) paced & Chamber(s) sensed & Mode(s) of response & Programmable functions & Anti-tachycardia function \\
V-Ventricle & V-Ventricle & T-Triggered & R-Rate Adaptive/Responsive & O-None \\
A-Atrium & A-Atrium & I-Inhibited & C-Communicating & P-Paced \\
D-Dual (A\&V) & D-Dual (A\&V) & D-Dual Triggered/Inhibited & M-Multi-programmable & S-Shocks \\
O-None (S-Single) & O-None (S-Single) & O-None & P-Simple Programmable & D-Dual (P\&S) \\
& & & O-None & \\
\hline
\end{tabular}

Table adapted from DeForge [17] 


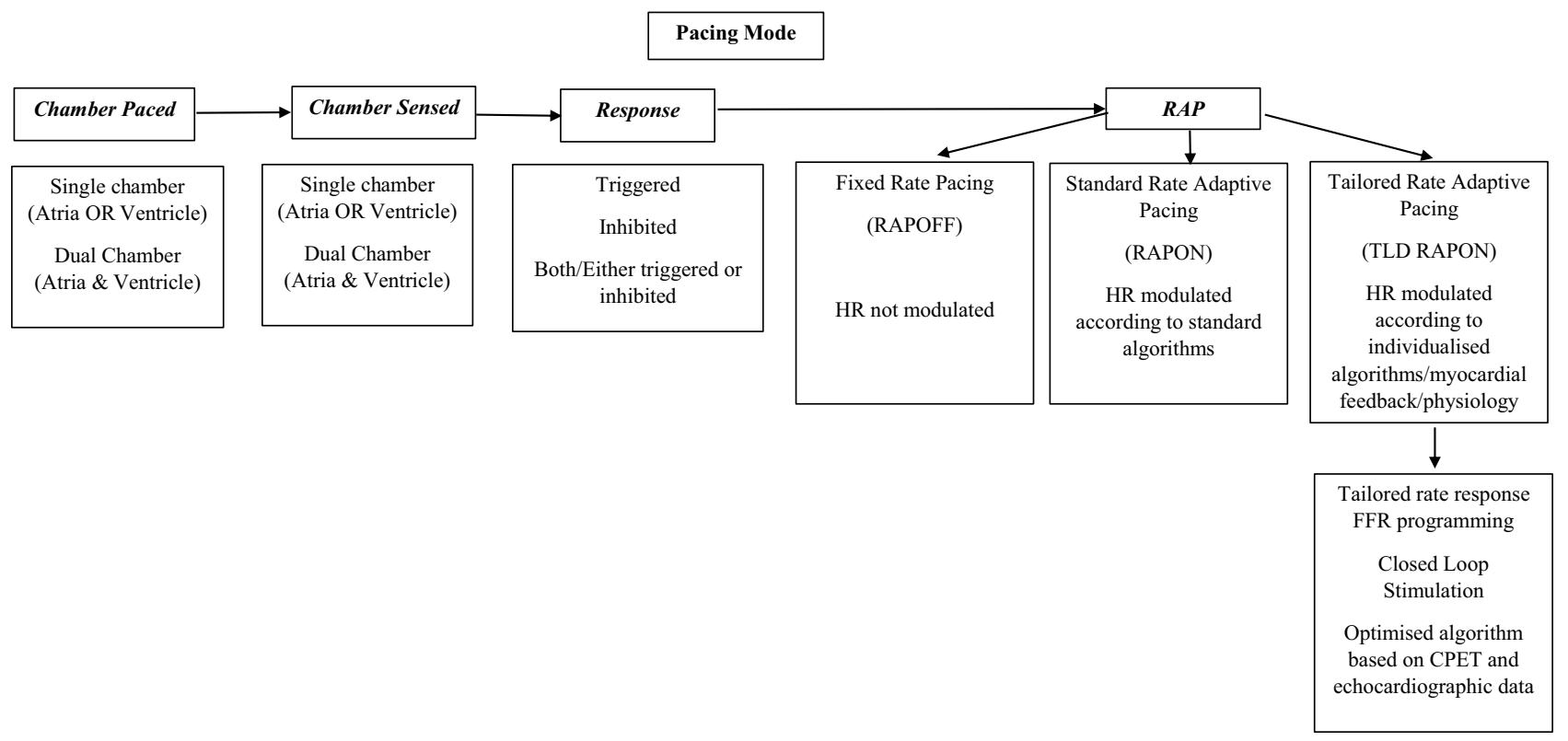

Fig. 2 Schematic diagram of pacing modes and difference between fixed rate pacing, rate adaptive pacing, and tailored rate adaptive pacing. Cardio-Pulmonary Exercise Test (CPET); Force Frequency Relationship (FFR); Heart Rate (HR)

prominent across HFrEF cohorts (13.3 [29]to 80\% [32]). Additionally, hypertension was present across a similar spectrum (28\% [22] to 86.7\% [32]). Beta blockers (BB) and ACE inhibitors/angiotensin receptor blockers (ACEI/ ARBS) were widely prescribed across the participants. Beta-blockers were most common at 82 [36] to $100 \%$ [5, 33] and ACEI/ARBs at 32.8 [22] to $100 \%$ [35] of participants, respectively. All four New York Heart Association (NYHA) classes were represented across the studies.

All but two studies [31,34] identifiably reported on people with HFrEF. The mean left ventricular ejection fraction (LVEF) in people with HFrEF across the studies was reported from 17 [35] to 39.7\% [32]. Those with HFpEF had a LVEF $>50 \%$ [31], while Shanmugam et al. [34] in people of unknown heart failure phenotype reported a mean LVEF of $42.5 \%$. Two studies included participants with atrial fibrillation (AF). Specifically, Jamil et al. [22] included a separate group analysis of 26 participants with AF, while Palmisano et al. [32] included 60 participants with drug refractory permanent AF undergoing atrio-ventricular junction ablation. Six out of ten studies defined CI but in various ways [5, 22, 31, 32, 35, 36].

\section{Outcomes}

Data are presented below and in the supplementary file. Data are reported as mean (95\% confidence interval, $P$ value for test of significant difference).

\section{Peak heart rate}

Four studies assessed peak HR while undergoing cardiopulmonary exercise testing [5, 22, 33, 34]. A total of 123 participants were included in the RAPON group and RAPOFF group, respectively. The data supported RAPON in increasing peak HR compared to RAPOFF. The mean difference was $14.98 \mathrm{bpm}(7.98,21.97, P<0.0001)$, and level of heterogeneity was moderate $\left(I^{2}=39 \%\right)$ (Fig. 4$)$.

All studies demonstrated an increase in peak HR with RAPON compared to RAPOFF, with statistically significant differences established in three studies: Jamil et al. [22] in both HFrEF and AF and HFrEF and SR groups, and Passman et al. [33] and Van Thielen et al. [5] in HFrEF and SR participants. Both Jamil et al. [22] and Van Thielen et al. [5] demonstrated no CONIs overlap at the 95\% level, while all other CONI overlapped (supplementary file).

\section{Peak oxygen uptake (peak $\mathrm{VO}_{2}$ )}

Six studies assessed peak $\mathrm{VO}_{2}[5,22,31,33-35]$; however, only five are included in the pooled analysis due to the unpublished nature of Kass et al. [31]. There were a total of 132 participants in the RAPON and RAOFF groups, respectively. The data supported a lack of effect of RAPON on peak $\mathrm{VO}_{2}$. The mean difference was $0.45 \mathrm{ml} \mathrm{kg}^{-1} \mathrm{~min}^{-1}$ $(-0.55,1.47 ; P=0.38)$, level of heterogeneity was low $\left(I^{2}=0 \%\right)$ (Fig. 5). 
Table 2 Characteristics of included studies standard RAP (RAPON) vs fixed rate pacing (RAPOFF)

\begin{tabular}{|c|c|c|c|c|c|c|c|c|c|}
\hline Study (year) & $\begin{array}{l}\text { Sample } \\
\text { size }\end{array}$ & HF type & Rhythm & CI criteria & Device type & Sensor & $\begin{array}{l}\text { Pacemaker } \\
\text { mode } \\
\text { (RAPON/ } \\
\text { RAPOFF)* }\end{array}$ & RAPON & RAPOFF \\
\hline Jamil et al. [22] & 79 & HFrEF & $\begin{array}{l}\text { SR (53) } \\
\text { AF (26) }\end{array}$ & $\begin{array}{l}\text { Chronotropic } \\
\text { index }<0.80\end{array}$ & $\begin{array}{l}\text { CRT } \\
\text { PM } \\
\text { ICD }\end{array}$ & $\begin{array}{l}\text { Unknown } \\
\text { sensor }\end{array}$ & $\begin{array}{l}>95 \% \mathrm{BiV} \\
\text { pacing } \\
\text { (CRT) } \\
0 \% \text { ven- } \\
\text { tricular } \\
\text { pacing } \\
\text { (non } \\
\text { CRT) }\end{array}$ & RAPON & RAPOFF \\
\hline Kass et al. [31] & 13 & HFpEF & SR & $\begin{array}{l}\leq 80 \% \text { HRR } \\
\leq 62 \% \text { HRR in } \\
\text { those tx BB }\end{array}$ & $\begin{array}{l}\text { Implantable } \\
\text { cardiac } \\
\text { device }\end{array}$ & $\begin{array}{l}\text { Blended } \\
\text { minute } \\
\text { ventilation } \\
\text { and accel- } \\
\text { erometer }\end{array}$ & AAIR/AAI & AAIR & AAI \\
\hline $\begin{array}{l}\text { Palmisano et al. } \\
\text { [32] }\end{array}$ & 60 & $\begin{array}{l}\text { HFrEF } \\
\text { with drug } \\
\text { refractory } \\
\text { AF }\end{array}$ & $\begin{array}{l}\text { AVJ Abla- } \\
\text { tion and } \\
\text { BiV pac- } \\
\text { ing }\end{array}$ & $\begin{array}{l}100 \% \\
\text { iatrogenic CI } \\
\text { after AV nodal } \\
\text { ablation }\end{array}$ & CRT & $\begin{array}{l}\text { Accelerom- } \\
\text { eter }\end{array}$ & VVIR/VVI & VVIR & VVI \\
\hline $\begin{array}{l}\text { Passman et al. } \\
\text { [33] }\end{array}$ & 10 & HFrEF & SR & No CI Criteria & $\begin{array}{l}\text { Dual cham- } \\
\text { ber ICD }\end{array}$ & $\begin{array}{c}\text { Acceler- } \\
\text { ometer/ } \\
\text { Crystal }\end{array}$ & AAIR/VVI & AAIR & VVI \\
\hline Pu et al. [12] & 72 & HFrEF & SR & No CI Criteria & $\begin{array}{l}\text { Three } \\
\text { chamber } \\
\text { CRT-PM/ } \\
\text { ICD } \\
\text { Dual cham- } \\
\text { ber PM }\end{array}$ & $\begin{array}{l}\text { Unknown } \\
\text { Sensor }\end{array}$ & $\begin{array}{l}\text { RAAVD } \\
\text { LUV/BiV }\end{array}$ & $\begin{array}{l}\text { RAAVD } \\
\text { LUV } \\
\text { (RAP- } \\
\text { ON) }\end{array}$ & $\begin{array}{l}\text { BiV Pacing } \\
\text { (RAP- } \\
\text { OFF) }\end{array}$ \\
\hline $\begin{array}{c}\text { Shanmugam } \\
\text { et al. [34] }\end{array}$ & 20 & $\mathrm{HF}$ & SR & No CI Criteria & $\begin{array}{l}\text { CRT-PM/ } \\
\text { ICD }\end{array}$ & $\begin{array}{l}\text { Unknown } \\
\text { sensor }\end{array}$ & $\begin{array}{l}\text { RAAVD } \\
\text { LUV/BiV }\end{array}$ & $\begin{array}{l}\text { RAAVD- } \\
\text { ON }\end{array}$ & BiV Pacing \\
\hline Sims et al. [35] & 13 & HFrEF & SR & $<70 \%$ APMHR & CRT & $\begin{array}{l}\text { Unknown } \\
\text { sensor }\end{array}$ & $\begin{array}{c}\text { DDDR/ } \\
\text { DDD }\end{array}$ & DDDR & DDD \\
\hline Tse et al. [36] & 20 & HFrEF & SR & $\begin{array}{c}<70 \% \text { APMHR } \\
(n=11) / 70 \%- \\
85 \% \text { APMHR } \\
(n=9)\end{array}$ & $\begin{array}{c}\text { CRT-PM } \\
(n=7) \\
\text { CRT-ICD } \\
(n=3) \\
\text { CRT } \\
(n=10)\end{array}$ & $\begin{array}{l}\text { Accelerom- } \\
\text { eter }\end{array}$ & $\begin{array}{c}\text { DDDR/ } \\
\text { DDD }\end{array}$ & DDDR & DDD \\
\hline $\begin{array}{c}\text { Van Thielen } \\
\text { et al. [5] }\end{array}$ & 14 & HFrEF & SR & $<85 \%$ APMHR & CRT & $\begin{array}{l}\text { Unknown } \\
\text { sensor }\end{array}$ & $\begin{array}{c}\text { DDDR/ } \\
\text { DDD }\end{array}$ & DDDR & DDD \\
\hline Zhao et al. [29] & 60 & HFrEF & SR & No CI Criteria & $\begin{array}{l}\text { Three- } \\
\text { chamber } \\
\text { PM } \\
\text { Dual cham- } \\
\text { ber PM }\end{array}$ & $\begin{array}{l}\text { Unknown } \\
\text { sensor }\end{array}$ & $\begin{array}{l}\text { RAAVD } \\
\text { LUV/BiV }\end{array}$ & RAAVD & BiV pacing \\
\hline
\end{tabular}

$A F$ atrial fibrillation, $A P M H R$ age predicted maximum heart rate, $A V$ atrio-ventricular, $A V J$ atrio-ventricular junction, $B B$ beta-blockers, $B i V$ biventricular, $C I$ chronotropic incompetence, $C R T$ cardiac resynchronisation therapy, $H F$ heart failure, $H F p E F$ heart failure preserved ejection fraction, $H F r E F$ heart failure reduced ejection fraction, $H R R$ heart rate reserve, $I C D$ implantable cardio-defibrillator, $L U V$ left univentricular, $P M$ pacemaker, $R A A V D$ rate adaptive atrioventricular delay, $R A P$ rate adaptive pacing, $R A P O F F$ fixed rate pacing, $R A P O N$ standard rate adaptive pacing, $S R$ sinus rhythm

Only two studies demonstrated a significant increase in peak $\mathrm{VO}_{2}$ with RAPON compared to RAPOFF. Jamil et al. [22] demonstrated a significant increase in peak $\mathrm{VO}_{2}$ in the
HFrEF and AF group; however, this was not reflected in the HFrEF and SR group. Shanmugam et al. [34] observed a significant increase in peak $\mathrm{VO}_{2}$ with $\mathrm{RAAVD}$ compared 


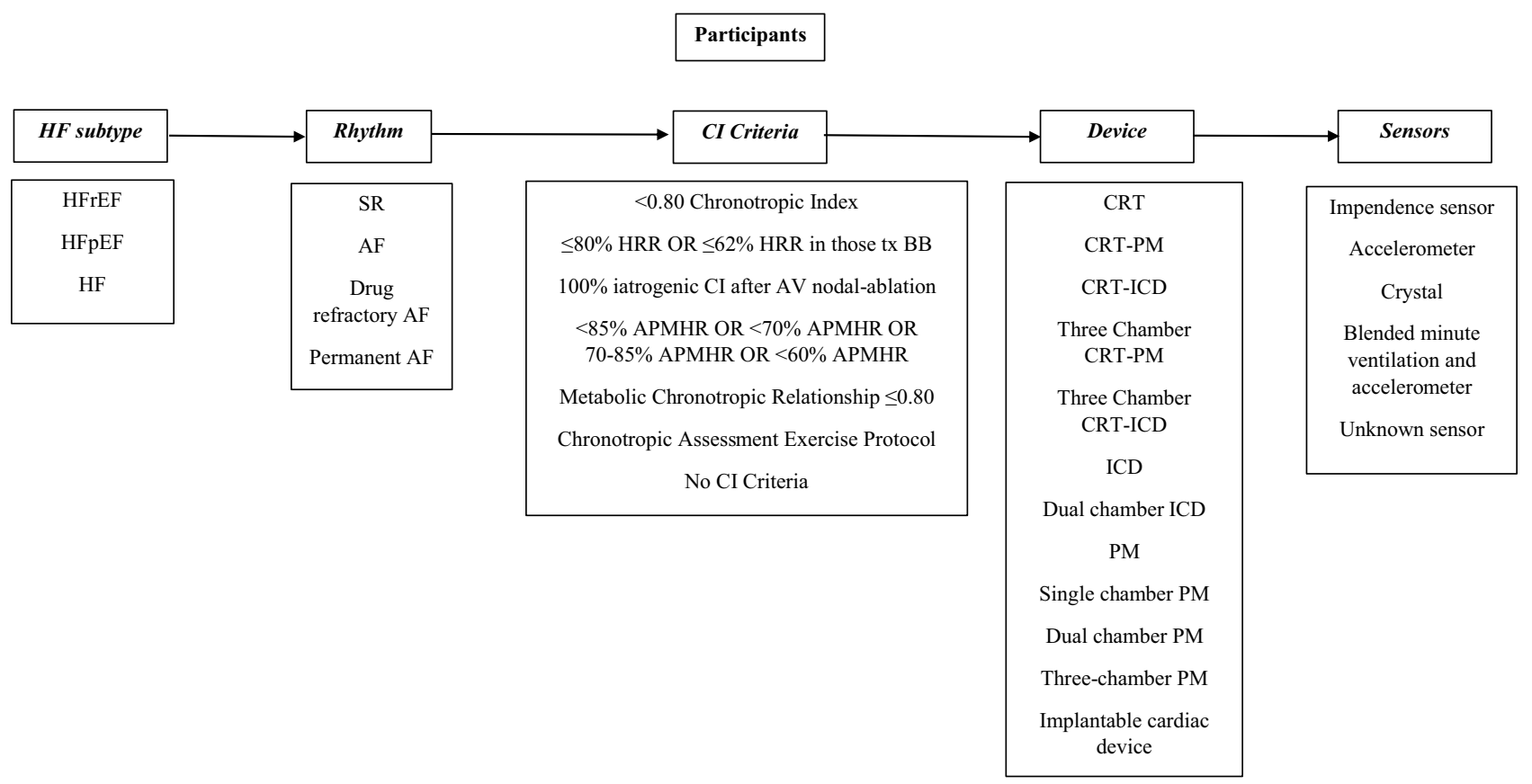

Fig. 3 Overview of participant characteristics across all included studies. Atrial fibrillation (AF), age predicted maximum heart rate (APMHR), atrio-ventricular (AV), beta-blockers (BB), chronotropic incompetence $(\mathrm{CI})$, cardiac resynchronisation therapy (CRT), heart failure (HF), heart failure preserved ejection fraction (HFpEF), heart failure reduced ejection fraction (HFrEF), heart rate reserve (HRR), implantable cardio-defibrillator (ICD), pace maker (PM), sinus rhythm (SR)

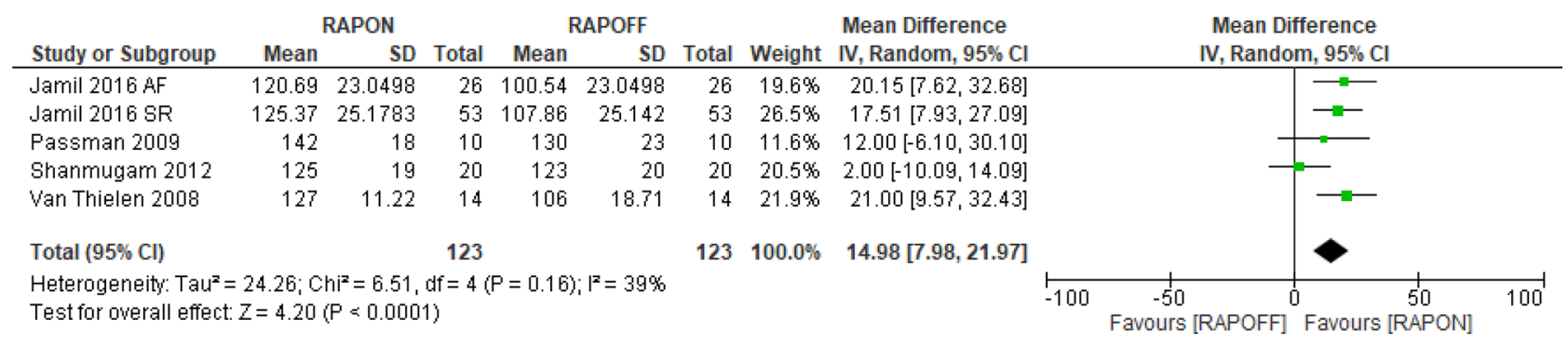

Fig. 4 Peak HR RAPON vs RAPOFF

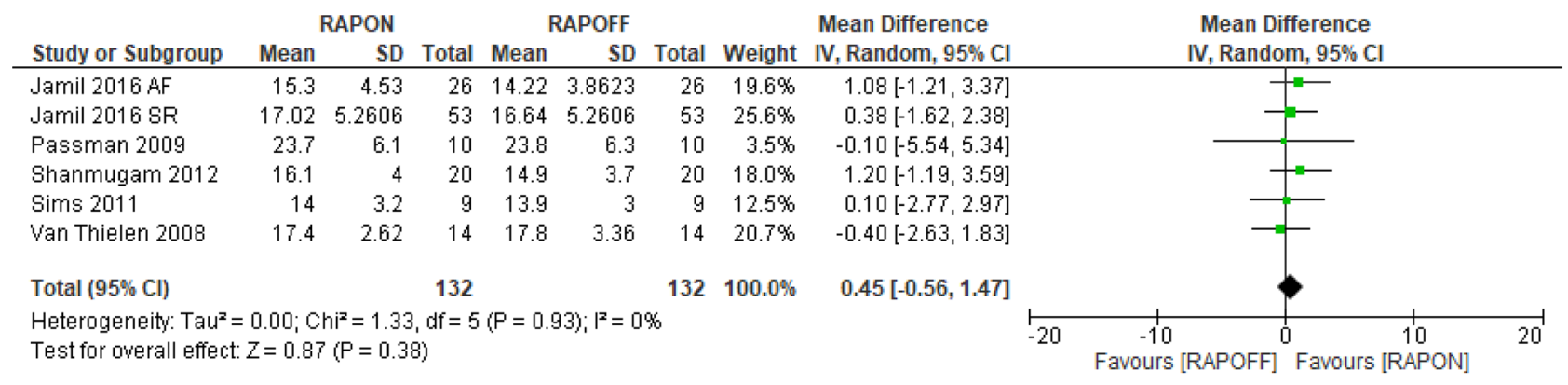

Fig. 5 Peak $\mathrm{VO}_{2}$ RAPON vs RAPOFF 
to standard $\mathrm{BiV}$ pacing. All CONIs overlapped at the $95 \%$ and $84 \%$ levels (supplementary file).

\section{Exercise time}

Three studies assessed ET during peak $\mathrm{VO}_{2}$ assessment. All were included in the pooled analysis. There were a total of 109 participants in the RAPON and RAPOFF groups. The data demonstrated a non-significant increase in ET with RAPON compared to RAPOFF. The mean difference was $9.74 \mathrm{~s}(-48.78,68.26 ; P=0.74)$; level of heterogeneity was low $\left(I^{2}=0 \%\right)$ (Fig. 6).

Only one study demonstrated a significant increase in ET with RAPON compared to RAPOFF. Shanmugam et al. [34] observed an increase in ET of $48 \mathrm{~s}$ in people with HF in SR with RAAVD compared to standard BiV pacing. All CONIs overlapped at the $95 \%$ and $84 \%$ levels (supplementary file).

\section{Six-min walk test}

Four studies assessed exercise capacity using 6MWT [12, $29,32,35]$. Differing study designs did not permit pooled analysis. All studies demonstrated an increase in the 6MWT with RAPON compared to RAPOFF. However, only two studies demonstrated a significant increase in distance including Palmisano et al. [32] (HFrEF and atrioventricular junction ablation for AF) and Sims et al. [35] (HFrEF and SR). All studies demonstrated CONIs crossed over at both the $95 \%$ and $84 \%$ levels (supplementary file).

\section{Tailored rate adaptive pacing vs standard rate adaptive pacing}

\section{Study characteristics}

Three studies compared tailored RAP programming (TLD RAPON) with standard RAP (RAPON) (Table 3) [6, 21, 30]. Two studies were randomised control trials [6,21]. Devices included single or dual chamber PM, CRT, and ICD. Modes include VVIR, DDDR, and AAIR. One study employed a closed loop stimulation/impedance sensor in the TLD
RAPON group comparing it to a standard accelerometer [30] (RAPON). Serova et al. [21] utilised a PM with an accelerometer. Gierula et al. [6] did not identify the sensor use.

Of the three studies comparing tailored RAP (TLD RAPON) to standard RAP (RAPON) (Table 2), Gierula et al. [6] compared a tailored rate response force-frequencyrelationship (FFR) algorithm (TLD RAPON) with standard rate response programming (RAPON). Hsu et al. [30] compared closed loop stimulation (CLS/impedance sensor) (TLD RAPON) vs standard DDDR mode (accelerometer sensor) (RAPON). While Serova et al. [21] compared an optimised algorithm for RAP based on CPET and PM stress echocardiography data (TLD RAPON) with conventional RAP programming (RAPON).

\section{Participant characteristics}

Two studies reported on people with HFrEF, with the mean LVEF 35.2 [6] to 37\% [30]. Serova et al. [21] reported a LVEF of $51-53 \%$ in people with HFpEF. All studies included participants with AF including Hsu et al. [30] (18\% paroxysmal AF), Gierula et al. [6] (36\% unspecified AF), and Serova et al. [21] (100\% permanent AF). Two the studies defined CI [21, 30]. NYHA classes I-III are represented across the studies.

The mean age of participants ranged from 69 [30] to 74 years [6]. Serova et al. [21] conducted an HFpEF study, reporting a higher proportion of females $(54.5 \%)$. Males made up 56 [30] to $71 \%$ [6] in studies including people with HFrEF. Ischemic aetiology was presented in $63 \%$ of $\mathrm{HErEF}$ participants [6]. While hypertension was more prevalent in people with HFpEF (86\% [21] vs 47\% [6]). BB and ACEI/ ARBS were widely prescribed across the participants. BB were most common at 86 [21] to 96\% [6] and ACEI/ARBs at 77 [21] to $94 \%$ [6] of participants, respectively.

\section{Outcomes}

Differences in study design (2 randomised control trials; 1 cross over trials) did not allow for data pooling. Data from all studies is presented in the supplementary files.

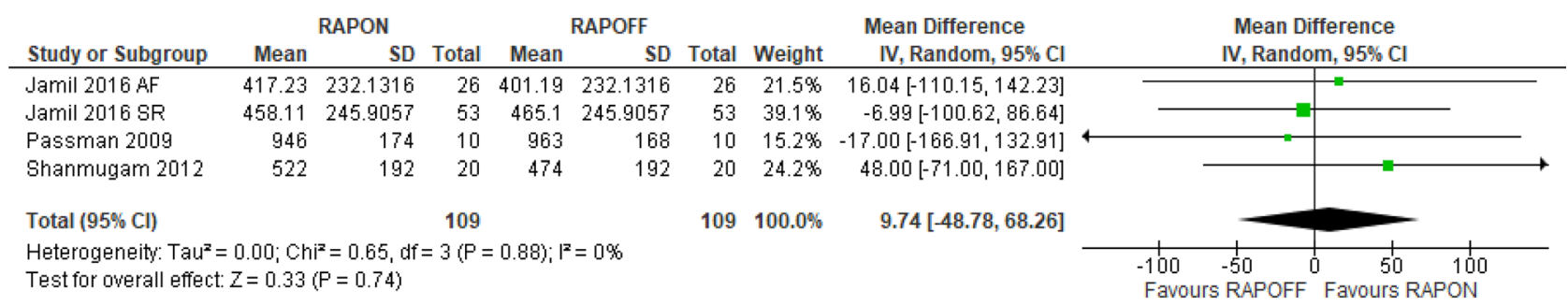

Fig. 6 ET RAPON vs RAPOFF 
Table 3 Characteristics of included studies: tailored RAP (TLD RAPON) vs standard RAP (RAPON)

\begin{tabular}{|c|c|c|c|c|c|c|c|c|c|}
\hline Study (year) & Sample size & HF type & Rhythm & CI criteria & Device type & Sensor & $\begin{array}{l}\text { Pacemaker } \\
\text { mode } \\
\text { (RAPON } \\
\text { Tailored/ } \\
\text { RAPON } \\
\text { Standard)* }\end{array}$ & $\begin{array}{l}\text { TLD } \\
\text { RAPON }\end{array}$ & RAPON \\
\hline $\begin{array}{l}\text { Gierula } \\
\text { et al. [6] }\end{array}$ & 83 & HFrEF & $\begin{array}{l}\mathrm{SR}(53) \\
\mathrm{AF}(30)\end{array}$ & $\begin{array}{l}\text { No CI cri- } \\
\text { teria }\end{array}$ & CRT or ICD & $\begin{array}{l}\text { Unknown } \\
\text { sensor }\end{array}$ & $\begin{array}{l}\text { VVIR (AF) } \\
\text { DDDR (CRT) } \\
\text { AAIR (no } \\
\text { CRT) } \\
\text { DDDR (no } \\
\text { CRT + long } \\
\text { AVD) }\end{array}$ & $\begin{array}{l}\text { Tailored } \\
\text { rate } \\
\text { response } \\
\text { FFR } \\
\text { program- } \\
\text { ming }\end{array}$ & $\begin{array}{l}\text { Conven- } \\
\text { tional rate } \\
\text { response } \\
\text { program- } \\
\text { ming }\end{array}$ \\
\hline $\begin{array}{l}\text { Hsu et al. } \\
{[30]}\end{array}$ & 12 & $\mathrm{HFrEF}$ & SR & $\begin{array}{l}\text { Metabolic } \\
\text { chrono- } \\
\text { tropic } \\
\text { relation- } \\
\text { ship } \leq 0.80\end{array}$ & CRT-ICD & $\begin{array}{l}\text { Impendence } \\
\text { sensor/ } \\
\text { standard } \\
\text { acceler- } \\
\text { ometer }\end{array}$ & DDDR/CLS & $\begin{array}{l}\text { Closed loop } \\
\text { stimula- } \\
\text { tion }\end{array}$ & $\begin{array}{r}\text { Standard } \\
\text { DDDR } \\
\text { pacing }\end{array}$ \\
\hline $\begin{array}{l}\text { Serova et al. } \\
{[21]}\end{array}$ & 54 & $\begin{array}{l}\text { HFpEF with } \\
\text { permanent } \\
\text { AF }\end{array}$ & $\mathrm{AF}$ & $\begin{array}{c}\text { Chronotropic } \\
\text { assessment } \\
\text { exercise } \\
\text { Protocol }^{84}\end{array}$ & $\begin{array}{l}\text { Single } \\
\text { chamber } \\
\text { PM }\end{array}$ & $\begin{array}{l}\text { Accelerom- } \\
\text { eter }\end{array}$ & VVIR & $\begin{array}{l}\text { Optimised } \\
\text { algorithm } \\
\text { based on } \\
\text { CPET and } \\
\text { echocar- } \\
\text { diographic } \\
\text { data }\end{array}$ & $\begin{array}{l}\text { Conventional } \\
\text { age-based } \\
\text { program- } \\
\text { ming }\end{array}$ \\
\hline
\end{tabular}

$A F$ atrial fibrillation, $A P M H R$ age predicted maximum heart rate, $C I$ chronotropic incompetence, $C L S$ closed loop stimulation, $C P E T$ cardiopulmonary exercise training, $C R T$ cardiac resynchronisation therapy, $F F R$ force frequency relationship, $H F$ heart failure, $H F p E F$ heart failure preserved ejection fraction, $H F r E F$ heart failure reduced ejection fraction, $I C D$ implantable cardio-defibrillator, $P M$ pacemaker, $R A P$ rate adaptive pacing, RAPON standard rate adaptive pacing, $S R$ sinus rhythm, TLD RAPON tailored rate adaptive pacing

\section{Peak HR}

Two studies comparing TLD RAPON vs RAPON modes reported peak HR while undergoing CPET [6, 30]. There was no significant difference between peak HR values for TLD RAPON vs RAPON reported in any study. All CONI overlapped at the $95 \%$ and $84 \%$ levels.

\section{Peak oxygen uptake (peak V02)}

All three studies comparing TLD RAPON vs RAPON modes reported peak $\mathrm{VO}_{2}[6,21,30]$. Two studies $[6,30]$ showed no improvement in peak $\mathrm{VO}_{2}$ with TLD RAPON vs RAPON. Only Serova et al. [21] demonstrated an increase in peak $\mathrm{VO}_{2}$ in people with $\mathrm{HFpEF}$ and AF with an optimised algorithm tailored to participants individual CPET and PM stress echocardiography data compared to standard RAPON programming. All CONIs overlapped at the $95 \%$ and $84 \%$ levels.

\section{ET}

Two studies assessed ET during peak $\mathrm{VO}_{2}$ assessment. Both studies demonstrate a significant increase in ET with TLD RAPON compared to RAPON. Gierula et al. [6] observed an increase in ET of $81 \mathrm{~s}(P=0.044)$ in people with $\mathrm{HFrEF}$ in SR or AF, while Serova et al. [21] observed an increase in ET of $147 \mathrm{~s}(P<0.0001)$ in people with HFpEF and AF. All CONIs overlapped at the $95 \%$ and $84 \%$ levels (supplementary file).

\section{Six-minute walk test}

Serova et al. [21] was the only TLD RAPON vs RAPON study to assess 6MWD. There was no significant change between tailored and standard RAP with CONIs demonstrating cross over at the $95 \%$ and $84 \%$ levels.

\section{Discussion}

We conducted a systematic review and data synthesis of studies comparing the effects of RAP on exercise capacity in people with CHF. RAP is largely indicated for people with CI, which is prevalent in $30-50 \%$ of people with $\mathrm{CHF}$ $[8,11]$. We separated our analyses into studies comparing RAPON vs RAPOFF and those comparing TLD RAPON vs RAPON. The main findings from this review are that it is evident that RAPON increases peak HR in people with $\mathrm{CHF}$, the key feature of this modality. Although, the increase in 
peak HR occurs without a concomitant improvement peak $\mathrm{VO}_{2}$, suggesting that $\mathrm{CI}$ is not related to exercise capacity in people with CHF [22,37]. This is contrary to the positive relationship between $\mathrm{HR}$ and $\mathrm{VO}_{2}$ in healthy individuals. Consequently, there seems to be an uncoupling of peak HR and peak exercise capacity in people with CHF [38].

\section{Heart rate}

Heart rate acutely regulates myocardial contractile state and subsequently cardiac output. The force frequency relationship (FFR) is intrinsic to human cardiomyocytes and governs that an increase in HR increases contractile function [39]. The intrinsic molecular integration of cardiomyocytes facilitates an increase in acceleration of shortening and relengthening that optimises filling time and increases systolic force with shortened cycle length. This positive FFR is critical to maintaining adequate cardiac output to meet metabolic demands [29, 39, 40]. However, the FFR is impaired in senescent human cardiomyocytes that may parallel the physiological decrement in peak HR with age [39, 40].

The FFR is especially diminished in diseased myocardium, suggesting that higher peak HRs in people with CHF may not be conducive to the underlying pathophysiology [41]. Although CI in people with CHF is associated with increased HF hospitalisation and mortality [11], it has been suggested that CI may be a compensatory mechanism to avoid an increase in myocardial work at the expense of cardiac output [22]. Limiting the maximum HR achievable is important to minimise ischemia [42, 43], myocyte apoptosis [44, 45], and cardiac remodelling [46]. For instance, Gierula and colleagues [6] tailoring RAP (TLD RAPON) according to individuals FFR significantly reduced peak HR by $13 \mathrm{bpm}$ when compared to RAPON. This occurred in the setting of increased exercise time (ET) without a concomitant increase in peak $\mathrm{VO}_{2}$. This indicates that a lower exercise HR, facilitating an optimal FFR in people with CHF, may promote an increase in work output without increasing oxygen demands. A consequence of increased myocardial efficiency and optimal cardiac output $[6,7,47]$.

Due to central and peripheral limitations, people with CHF rely disproportionately on their HRR to augment cardiac output and thus peak $\mathrm{VO}_{2}$. Therefore, HRR demonstrates strong prognostic value in this population [48, 49]. Bangalore et al. [49] showed that \%HRR was a good measure of $\mathrm{CI}$ and has further prognostic value than $85 \% \mathrm{APMHR}$ and other standard cardiovascular risk factors. In addition, $\%$ HRR was also independent of echocardiograpically determined myocardial ischemia and LVEF, and was an independent predictor of cardiovascular events. As HRR is determined by the difference between resting and peak HR, this measure may be more applicable to the FFR, representing a shift down the curve [50]. Therefore, people with CHF have a reduced intrinsic myocardial capacity for increased contractility [51].

The importance of enhancing HRR in people with CHF is reflected in prescription of beta-adrenergic blocking (BB)-agents as cornerstone therapy [52]. CHF pathology is associated with sympathetic overdrive that leads to a down regulation and desensitisation of beta-adrenergic receptors [53-55]. BB-prescription is associated with the subsequent upregulation of beta-adrenergic receptors that might conserve inotropy and chronotropy by lowering resting HR [56, 57]. A lower resting HR and greater HRR is correlated with improvements in exercise capacity, central hemodynamics, and prognosis in people with CHF [58]. Carvalho and colleagues [59] demonstrated that the relationship between the $\% \mathrm{VO}_{2}$ reserve and \%HRR in CHF patients on optimised BBtherapy was reliable, but this relationship was unreliable in non-optimised CHF patients. This indicates an intrinsic link between reducing myocardial work, improving adrenergic sensitivity and contractility [60]. Also, increased myocardial work at lower intensities may reflect an impaired FFR such that higher HRs are required to maintain adequate cardiac output at reduced metabolic loads. Thereby improving adrenergic sensitivity and increasing vagal tone may consequently improve filling time and systolic force reducing myocardial work for any given intensity. This is reflected in studies on calcium handling in failing and non-failing cardiomyocytes [39, 40, 61, 62]. Efficient calcium handling is critical to maximising filling time with increasing HRs that in turn enhances systolic function. Senescent and failing cardiomyocytes exhibited prolonged calcium handling dynamics with increased pacing frequency which correlated with impaired cell shortening and re-lengthening frequency [39]. Therefore, significantly reducing resting HR may allow for increased filling time and improved myocardial efficiency [62]. For example, Bagriy et al. [63] demonstrated that adding ivabradine to carvedilol therapy in people with CHF significantly lowered resting HR and improved 6MWT and LVEF compared to people with CHF and carvedilol therapy alone.

\section{Exercise capacity}

\section{Peak exercise capacity}

Peak exercise capacity did not improve with RAP compared to fixed rate pacing in people with CHF. Possible limiting factors of exercise capacity in people with CHF and IECD with RAP are presented by the Fick equation. It can be postulated that as there was no observed change in peak $\mathrm{VO}_{2}$, then arterio-venous difference limits oxygen consumption $[64,65]$. Alternatively, cardiac output may be similar in RAPON compared to RAPOFF due to the inability of the 
failing myocardium to produce an increase in stroke volume at higher HRs $[2,38]$.

The stunting of exercise capacity in people with CHF and RAP may be due to unfavourable peripheral hemodynamics and skeletal muscle function [15]. Van Thielen et al. [5] observed an increase in cardiac output and peak HR without a concomitant improvement in peak $\mathrm{VO}_{2}$, suggesting a peripheral limitation in exercise capacity. In contrast, it has been proposed that $\mathrm{CI}$ in people with CHF may be an important compensatory mechanism to ensure cardiac output is not overtly diminished compared to metabolic requirements [10]. Higher peak HRs in people with CHF may negatively impact the FFR, compromising cardiac output, limiting exercise capacity [66]. Kinderman and colleagues [38] demonstrated that the optimal pacing rate for oxygen uptake in people with CHF is significantly lower than in people with normal left ventricular function, specifically, $75 \%$ APMHR. However, as no other studies in this review besides Van Thielen et al. [5] measured cardiac output or an echocardiographic surrogate at peak exercise, this hypothesis cannot be corroborated.

\section{Submaximal exercise capacity}

Peak $\mathrm{VO}_{2}$ may not be the most clinically relevant outcome of RAP in people with CHF. Some have argued that peak CPET in people with CHF is unnecessary [67-69]. The level of exertion required to validate the test is unable to be met in this population due to a number of limiting factors such as CI itself, ventilation rate, pulmonary congestion, and leg fatigue $[10,70]$. Alternatively, the 6MWT may be more relevant to assess capacity to perform activities of daily living, holding greater relevance when assessing RAP $[67,71]$. In this review, all studies comparing RAPON vs RAPOFF demonstrated a trend towards an improvement in 6MWT $[12,29,32,35]$ and two studies observed a significant increase [32, 35]. This may reflect the rate control of RAP, which mimics a more physiological rise in HR in the early stages of exercise, compared to a standard linear increase in RAPOFF. This may facilitate optimal cardiac output at submaximal workloads. Sims et al. [35] demonstrated clearly the early rise in HR at the commencement of exercise facilitated by RAPON compared to RAPOFF during a graded maximal exercise test. This early rise in HR may have greater relevance for submaximal exercise, enabling a greater work output without increasing $\mathrm{VO}_{2}$ by optimising cardiac dynamics further down the FFR curve [7, 35, 47]. Additionally, Palmisano et al. [32] observed a significant increase in the 6MWT in RAPON mode compared to RAPOFF mode, with HR $30 \mathrm{bpm}$ higher while systolic blood pressure was $9 \mathrm{mmHg}$ lower for RAPON vs RAPOFF, respectively. This suitably reflects an optimal FFR such that
HR increase does not exceed the critical point at which contractility and stroke volume diminish. Thus, contractility and cardiac output may be optimal with RAP at submaximal intensities which could have important implications for activities of daily living [72].

\section{Limitations}

Studies included in this review had variation among CI criteria, pacing types, modes, and programming that may reduce an observable impact of RAP [1, 73, 74]. For example, Serova et al. [21] only included participants with HFpEF in AF with single chamber PM in VVIR mode with an accelerometer. Importantly, VVI(R) pacing has been shown to have lesser improvements over dual chamber and $\mathrm{BiV}$ pacing in terms of improvement in functional status and HF symptoms, dysynchrony, and cardiac remodelling. Similarly, the presence of $\mathrm{RV}$ pacing presents an issue when interpreting results of pacing studies as it induces dysynchrony and enhances LV dysfunction [75, 76]. Additionally, combined sensors such as blended minute ventilation and accelerometers have been shown to have superior HR modulation compared to single sensors [77, 78]. Therefore, care should be taken before extrapolating these results to people with $\mathrm{HFrEF}$ in SR, and those with PM in DDDR mode, CRT devices, or PM with other types of activated sensors. Also, the long-term effects of RAP are yet to be elucidated. Only one study to date has conducted long-term follow-up of people with CHF and RAP, with non-applicable results due to RV pacing [79].

\section{Future research}

RAP may have important applications beyond attenuating CI [21]. Exercise training (ET) in people with CHF has been shown to have positive central and peripheral adaptations with minimal adverse events [80-82]. Therefore, future research should the assess the effects of RAP in ET in people with CHF and IECD, including long-term follow-up to ascertain if RAP is in anyway detrimental in this population. Additionally, as RAP may have greater implications at submaximal intensities, future research should ascertain if RAP improves efficiency by lowering $\mathrm{VO}_{2}$ for a given workload.

\section{Conclusion}

The results of this systematic review confirm that RAP increases peak HR in people with CHF, however there is no concomitant improvement peak $\mathrm{VO}_{2}$. Therefore, $\mathrm{CI}$ may not be associated with exercise intolerance in people with CHF. Rather HRR, as an indication of a reserve in myocardial 
contractility, rather than peak HR, may be of greater importance in people with CHF. Consequently, people with CHF have an impaired FFR that may be optimised by lowering resting HR rather than inducing an increase in peak HR. Additionally, HR at rest and at submaximal intensities may be an important indicator of myocardial efficiency, indirectly reflecting patients' FFR, providing valuable information for CHF management. In the case of RAP, its application may be better suited at modulating the rise in HR at submaximal intensities rather than increasing peak HR.

Supplementary Information The online version contains supplementary material available at https://doi.org/10.1007/s10741-022-10217-x.

Author contribution Prof. Smart was the team leader, who also assisted with study inclusion/exclusion, data extraction/analysis, and writing and editing of both the main text and supplementary files. Dr. Melissa Pearson is a post-doctoral researcher who contributed to the initial idea conception, conducted much of the data extraction, study quality assessment, and assisted with manuscript writing. Miss Hannah Clark is a PhD candidate who conducted the searches, contributed to the initial idea conception, conducted most of the data extraction, study quality assessment, and led the manuscript writing.

Funding Open Access funding enabled and organized by CAUL and its Member Institutions.

Availability of data and material All data is available in the supplementary file.

\section{Declarations}

Ethics approval No ethics approval was required or this research.

Conflict of interest The authors declare no competing interests.

Open Access This article is licensed under a Creative Commons Attribution 4.0 International License, which permits use, sharing, adaptation, distribution and reproduction in any medium or format, as long as you give appropriate credit to the original author(s) and the source, provide a link to the Creative Commons licence, and indicate if changes were made. The images or other third party material in this article are included in the article's Creative Commons licence, unless indicated otherwise in a credit line to the material. If material is not included in the article's Creative Commons licence and your intended use is not permitted by statutory regulation or exceeds the permitted use, you will need to obtain permission directly from the copyright holder. To view a copy of this licence, visit http://creativecommons.org/licenses/by/4.0/.

\section{References}

1. Voskoboinik A, McGavigan AD, Mariani JA (2016) Cardiac resynchronisation therapy in 2015: keeping up with the pace. Intern Med J 46(3):255-265

2. Nguyên UC, Verzaal NJ, van Nieuwenhoven FA, Vernooy K, Prinzen FW (2018) Pathobiology of cardiac dyssynchrony and resynchronization therapy. Europace 20(12):1898-1909
3. Abudiab MM, Redfield MM, Melenovsky V, Olson TP, Kass DA, Johnson BD et al (2013) Cardiac output response to exercise in relation to metabolic demand in heart failure with preserved ejection fraction. Eur J Heart Fail 15(7):776-785

4. Obokata M, Olson TP, Reddy YNV, Melenovsky V, Kane GC, Borlaug BA (2018) Haemodynamics, dyspnoea, and pulmonary reserve in heart failure with preserved ejection fraction. Eur Heart J 39(30):2810-2821

5. Van Thielen G, Paelinck BP, Beckers P, Vrints CJ, Conraads VM (2008) Rate response and cardiac resynchronisation therapy in chronic heart failure: higher cardiac output does not acutely improve exercise performance: a pilot trial. Eur J Cardiovasc Prev Rehabil 15(2):197-202

6. Gierula J, Lowry JE, Paton MF, Cole CA, Byrom R, Koshy AO et al (2020) Personalized rate-response programming improves exercise tolerance after 6 months in people with cardiac implantable electronic devices and heart failure: a phase II study. Circulation 141(21):1693-1703

7. Gierula J, Paton MF, Lowry JE, Jamil HA, Byrom R, Drozd M et al (2018) Rate-response programming tailored to the forcefrequency relationship improves exercise tolerance in chronic heart failure. JACC Heart Fail 6(2):105-113

8. Abraham WT, Fisher WG, Smith AL, Delurgio DB, Leon AR, Loh E et al (2002) Cardiac resynchronization in chronic heart failure. N Engl J Med 346(24):1845-1853

9. Brubaker PH, Kitzman DW (2011) Chronotropic incompetence: causes, consequences, and management. Circulation 123(9):1010-1020

10. Zweerink A, van der Lingen ACJ, Handoko ML, van Rossum AC, Allaart CP (2018) Chronotropic incompetence in chronic heart failure. Circ Heart Fail 11(8):e004969

11. Smart NA, Clark H, Brubaker P, Witte KK, Jamil H, Gierula J, Patel HC, Pearson MJ (2021) Effects of chronotropic incompetence on exercise capacity in people with heart failure versus age-matched controls. Heart Fail Rev

12. Pu LJ, Wang Y, Zhao LL, Guo T, Li SM, Hua BT et al (2017) Left univentricular pacing for cardiac resynchronization therapy using rate-adaptive atrioventricular delay. J Geriatr Cardiol $14(2): 118-126$

13. Strik M, Regoli F, Auricchio A, Prinzen F (2012) Electrical and mechanical ventricular activation during left bundle branch block and resynchronization. J Cardiovasc Transl Res 5(2):117-126

14. Kazemisaeid A, Rezvanfard M, Sadeghian H, Lotfi Tokaldany M, Mardanloo AS, Fathollahi MS (2012) Comparison between tissue doppler imaging (TDI) and tissue synchronization imaging (TSI) in evaluation of left ventricular dyssynchrony in patients with advanced heart failure. Echocardiography 29(1):7-12

15. Del Buono MG, Arena R, Borlaug BA, Carbone S, Canada JM, Kirkman DL et al (2019) Exercise intolerance in patients with heart failure: JACC State-of-the-Art Review. J Am Coll Cardiol 73(17):2209-2225

16. Hussein AA, Wilkoff BL (2019) Cardiac implantable electronic device therapy in heart failure. Circ Res 124(11):1584-1597

17. McMeekin JD, Lautner D, Hanson S, Gulamhusein SS (1990) Importance of heart rate response during exercise in patients using atrioventricular synchronous and ventricular pacemakers. Pacing Clin Electrophysiol 13(1):59-68

18. Lazarus A, Mitchell K (1996) A prospective multicenter study demonstrating clinical benefit with a new accelerometer-based DDDR pacemaker. Dromos Dr Investigators Group. Pacing Clin Electrophysiol 19(11 Pt 2):1694-7

19. Page E, Defaye P, Bonnet JL, Durand C, Amblard A (2003) Comparison of the cardiopulmonary response to exercise in recipients 
of dual sensor DDDR pacemakers Versus a Healthy control group. Pacing Clin Electrophysiol 26(1p2):239-43

20. Abi-Samra FM, Singh N, Rosin BL, Dwyer JV, Miller CD (2013) Effect of rate-adaptive pacing on performance and physiological parameters during activities of daily living in the elderly: results from the CLEAR (Cylos Responds with Physiologic Rate Changes during Daily Activities) study. Europace 15(6):849-856

21. Serova M, Andreev D, Giverts I, Sazonova Y, Svet A, Kuklina $M$ et al (2020) A new algorithm for optimization of rate-adaptive pacing improves exercise tolerance in patients with HFpEF. Pacing Clin Electrophysiol 43(2):223-233

22. Jamil HA, Gierula J, Paton MF, Byrom R, Lowry JE, Cubbon $\mathrm{RM}$ et al (2016) Chronotropic incompetence does not limit exercise capacity in chronic heart failure. J Am Coll Cardiol 67(16): 1885-1896

23. Clark H, Rana R, Gow J, Pearson M, van der Touw T, Smart N (2021) Hospitalisation costs associated with heart failure with preserved ejection fraction (HFpEF): a systematic review. Heart Fail Rev

24. Mittal N, Bhandari M, Kumbhare D (2019) A tale of confusion from overlapping confidence intervals. Am J Phys Med Rehabil 98(1):81-83

25. Austin PC, Hux JE (2002) A brief note on overlapping confidence intervals. J Vasc Surg 36(1):194-195

26. MacGregor-Fors I, Payton ME (2013) Contrasting diversity values: statistical inferences based on overlapping confidence intervals. PLoS One 8(2):e56794-e

27. Lee DK, In J, Lee S (2015) Standard deviation and standard error of the mean. Korean J Anesthesiol 68(3):220-223

28. Sterne JAC, Savović J, Page MJ, Elbers RG, Blencowe NS, Boutron I et al (2019) RoB 2: a revised tool for assessing risk of bias in randomised trials. Bmj 366:14898

29. Zhao L, Zhao L, Pu L, Hua B, Wang Y, Li S et al (2017) Left univentricular pacing by rate-adaptive atrioventricular delay in treatment of chronic heart failure. Med Sci Monit 23:3971-3980

30. Hsu JC, Darden D, Alegre M, Birgersdotter-Green U, Feld GK, Hoffmayer KS et al (2020) Effect of closed loop stimulation versus accelerometer on outcomes with cardiac resynchronization therapy: the CLASS trial. J Interv Card Electrophysiol

31. Kass DA, Kitzman DW, Alvarez GE (2010) The restoration of chronotropic competence in heart failure patients with normal ejection fraction (RESET) study: rationale and design. J Card Fail 16(1):17-24

32. Palmisano P, Aspromonte V, Ammendola E, Dell'era G, Ziacchi $\mathrm{M}$, Guerra $\mathrm{F}$ et al (2017) Effect of fixed-rate vs. rate-RESPONSIve pacing on exercise capacity in patients with permanent, refractory atrial fibrillation and left ventricular dysfunction treated with atrioventricular junction aBLation and bivEntricular pacing (RESPONSIBLE): a prospective, multicentre, randomized, single-blind study. Europace 19(3):414-20

33. Passman R, Banthia S, Galvez D, Sheldon T, Kadish A (2009) The effects of rate-adaptive atrial pacing versus ventricular backup pacing on exercise capacity in patients with left ventricular dysfunction. Pacing Clin Electrophysiol 32(1):1-6

34. Shanmugam N, Prada-Delgado O, Campos AG, Grimster A, Valencia O, Baltabaeva A et al (2012) Rate-adaptive AV delay and exercise performance following cardiac resynchronization therapy. Heart Rhythm 9(11):1815-1821

35. Sims DB, Mignatti A, Colombo PC, Uriel N, Garcia LI, Ehlert FA et al (2011) Rate responsive pacing using cardiac resynchronization therapy in patients with chronotropic incompetence and chronic heart failure. Europace 13(10):1459-1463

36. Tse HF, Siu CW, Lee KL, Fan K, Chan HW, Tang MO et al (2005) The incremental benefit of rate-adaptive pacing on exercise performance during cardiac resynchronization therapy. J Am Coll Cardiol 46(12):2292-2297
37. Witte KK, Clark AL (2009) Chronotropic incompetence does not contribute to submaximal exercise limitation in patients with chronic heart failure. Int J Cardiol 134(3):342-344

38. Kindermann M, Schwaab B, Finkler N, Schaller S, Böhm M, Fröhlig G (2002) Defining the optimum upper heart rate limit during exercise: a study in pacemaker patients with heart failure. Eur Heart J 23(16):1301-1308

39. Lim CC, Apstein CS, Colucci WS, Liao R (2000) Impaired cell shortening and relengthening with increased pacing frequency are intrinsic to the senescent mouse cardiomyocyte. J Mol Cell Cardiol 32(11):2075-2082

40. Bavendiek U, Brixius K, Münch G, Zobel C, Müller-Ehmsen J, Schwinger RH (1998) Effect of inotropic interventions on the force-frequency relation in the human heart. Basic Res Cardiol 93(Suppl 1):76-85

41. Thackray SD, Ghosh JM, Wright GA, Witte KK, Nikitin NP, Kaye GC et al (2006) The effect of altering heart rate on ventricular function in patients with heart failure treated with beta-blockers. Am Heart J 152(4):713.e9-13

42. Cleland JG, Pennell DJ, Ray SG, Coats AJ, Macfarlane PW, Murray GD et al (2003) Myocardial viability as a determinant of the ejection fraction response to carvedilol in patients with heart failure (CHRISTMAS trial): randomised controlled trial. Lancet 362(9377): 14-21

43. Jourdain P, Funck F, Fulla Y, Hagege A, Bellorini M, Guillard $\mathrm{N}$ et al (2002) Myocardial contractile reserve under low doses of dobutamine and improvement of left ventricular ejection fraction with treatment by carvedilol. Eur J Heart Fail 4(3):269-276

44. Bristow MR, Ginsburg R, Minobe W, Cubicciotti RS, Sageman WS, Lurie K et al (1982) Decreased catecholamine sensitivity and beta-adrenergic-receptor density in failing human hearts. $\mathrm{N}$ Engl J Med 307(4):205-211

45. Lowes BD, Gilbert EM, Abraham WT, Minobe WA, Larrabee P, Ferguson D et al (2002) Myocardial gene expression in dilated cardiomyopathy treated with beta-blocking agents. N Engl J Med 346(18):1357-1365

46. Cice G, Tagliamonte E, Ferrara L, Iacono A (2000) Efficacy of carvedilol on complex ventricular arrhythmias in dilated cardiomyopathy: double-blind, randomized, placebo-controlled study. Eur Heart J 21(15):1259-1264

47. Vollmann D, Lüthje L, Schott P, Hasenfuss G, Unterberg-Buchwald C (2006) Biventricular pacing improves the blunted force-frequency relation present during univentricular pacing in patients with heart failure and conduction delay. Circulation 113(7):953-959

48. Azarbal B, Hayes SW, Lewin HC, Hachamovitch R, Cohen I, Berman DS (2004) The incremental prognostic value of percentage of heart rate reserve achieved over myocardial perfusion single-photon emission computed tomography in the prediction of cardiac death and all-cause mortality: superiority over $85 \%$ of maximal age-predicted heart rate. J Am Coll Cardiol 44(2):423-430

49. Bangalore S, Yao SS, Chaudhry FA (2006) Comparison of heart rate reserve versus $85 \%$ of age-predicted maximum heart rate as a measure of chronotropic response in patients undergoing dobutamine stress echocardiography. Am J Cardiol 97(5):742-747

50. Ujeyl A, Stevenson LW, West EK, Kato M, Liszkowski M, Campbell $P$ et al (2011) Impaired heart rate responses and exercise capacity in heart failure patients with paced baseline rhythms. J Cardiac Fail 17(3):188-195

51. Benes J, Kotrc M, Borlaug BA, Lefflerova K, Jarolim P, Bendlova $\mathrm{B}$ et al (2013) Resting heart rate and heart rate reserve in advanced heart failure have distinct pathophysiologic correlates and prognostic impact: a prospective pilot study. JACC Heart Fail 1(3):259-266

52. Kubon C, Mistry NB, Grundvold I, Halvorsen S, Kjeldsen SE, Westheim AS (2011) The role of beta-blockers in the treatment of chronic heart failure. Trends Pharmacol Sci 32(4):206-212 
53. Castro PF, Greig D, Pérez O, Moraga F, Chiong M, Díaz-Araya $\mathrm{G}$ et al (2003) Relation between oxidative stress, catecholamines, and impaired chronotropic response to exercise in patients with chronic heart failure secondary to ischemic or idiopathic dilated cardiomyopathy. Am J Cardiol 92(2):215-218

54. Madsen BK, Keller N, Christiansen E, Christensen NJ (1995) Prognostic value of plasma catecholamines, plasma renin activity, and plasma atrial natriuretic peptide at rest and during exercise in congestive heart failure: comparison with clinical evaluation, ejection fraction, and exercise capacity. J Card Fail 1(3):207-216

55. Nikolaidis LA, Trumble D, Hentosz T, Doverspike A, Huerbin R, Mathier MA et al (2004) Catecholamines restore myocardial contractility in dilated cardiomyopathy at the expense of increased coronary blood flow and myocardial oxygen consumption ( $\mathrm{MvO} 2$ cost of catecholamines in heart failure). Eur J Heart Fail 6(4):409-419

56. Colucci WS, Ribeiro JP, Rocco MB, Quigg RJ, Creager MA, Marsh JD et al (1989) Impaired chronotropic response to exercise in patients with congestive heart failure. Role of postsynaptic beta-adrenergic desensitization Circulation 80(2):314-323

57. Arnold RH, Kotlyar E, Hayward C, Keogh AM, Macdonald PS (2003) Relation between heart rate, heart rhythm, and reverse left ventricular remodelling in response to carvedilol in patients with chronic heart failure: a single centre, observational study. Heart 89(3):293-298

58. McAlister FA, Wiebe N, Ezekowitz JA, Leung AA, Armstrong PW (2009) Meta-analysis: beta-blocker dose, heart rate reduction, and death in patients with heart failure. Ann Intern Med 150(11):784-794

59. Carvalho VO, Guimarães GV, Bocchi EA (2008) The relationship between heart rate reserve and oxygen uptake reserve in heart failure patients on optimized and non-optimized beta-blocker therapy. Clinics (Sao Paulo) 63(6):725-730

60. Spadari RC, Cavadas C, de Carvalho A, Ortolani D, de Moura AL, Vassalo PF (2018) Role of beta-adrenergic receptors and sirtuin signaling in the heart during aging, heart failure, and adaptation to stress. Cell Mol Neurobiol 38(1):109-120

61. Böhm M, La Rosée K, Schmidt U, Schulz C, Schwinger RH, Erdmann E (1992) Force-frequency relationship and inotropic stimulation in the nonfailing and failing human myocardium: implications for the medical treatment of heart failure. Clin Investig 70(5):421-425

62. Schwinger RH, Böhm M, Erdmann E (1992) Inotropic and lusitropic dysfunction in myocardium from patients with dilated cardiomyopathy. Am Heart J 123(1):116-128

63. Bagriy AE, Schukina EV, Samoilova OV, Pricolota OA, Malovichko SI, Pricolota AV et al (2015) Addition of ivabradine to $\beta$-blocker improves exercise capacity in systolic heart failure patients in a prospective, open-label study. Adv Ther 32(2):108-119

64. Upadhya B, Haykowsky MJ, Eggebeen J, Kitzman DW (2015) Exercise intolerance in heart failure with preserved ejection fraction: more than a heart problem. J Geriatr Cardiol 12(3):294-304

65. Phillips SA, Vuckovic K, Cahalin LP, Baynard T (2015) Defining the system: contributors to exercise limitations in heart failure. Heart Fail Clin 11(1):1-16

66. Cotton JM, Kearney MT, MacCarthy PA, Grocott-Mason RM, McClean DR, Heymes C et al (2001) Effects of nitric oxide synthase inhibition on basal function and the force-frequency relationship in the normal and failing human heart in vivo. Circulation 104(19):2318-2323
67. Agarwala P, Salzman SH (2020) Six-Minute Walk Test: Clinical Role, Technique, Coding, and Reimbursement. Chest 157(3):603-611

68. Kay GN (1992) Quantitation of chronotropic response: comparison of methods for rate-modulating permanent pacemakers. J Am Coll Cardiol 20(7):1533-1541

69. Weber KT, Kinasewitz GT, Janicki JS, Fishman AP (1982) Oxygen utilization and ventilation during exercise in patients with chronic cardiac failure. Circulation 65(6):1213-1223

70. Tzanis G, Dimopoulos S, Agapitou V, Nanas S (2014) Exercise intolerance in chronic heart failure: the role of cortisol and the catabolic state. Curr Heart Fail Rep 11(1):70-79

71. Passantino A, Lagioia R, Mastropasqua F, Scrutinio D (2006) Short-term change in distance walked in $6 \mathrm{~min}$ is an indicator of outcome in patients with chronic heart failure in clinical practice. J Am Coll Cardiol 48(1):99-105

72. Nonogi H, Hess OM, Ritter M, Krayenbuehl HP (1988) Diastolic properties of the normal left ventricle during supine exercise. $\mathrm{Br}$ Heart J 60(1):30-38

73. DeForge WF (2019) Cardiac pacemakers: a basic review of the history and current technology. J Vet Cardiol 22:40-50

74. Trohman RG, Huang HD, Larsen T, Krishnan K, Sharma PS (2020) Sensors for rate-adaptive pacing: How they work, strengths, and limitations. J Cardiovasc Electrophysiol 31(11):3009-3027

75. Hesselson AB, Parsonnet V, Bernstein AD, Bonavita GJ (1992) Deleterious effects of long-term single-chamber ventricular pacing in patients with sick sinus syndrome: the hidden benefits of dual-chamber pacing. J Am Coll Cardiol 19(7):1542-1549

76. Lamas GA, Lee KL, Sweeney MO, Silverman R, Leon A, Yee R et al (2002) Ventricular pacing or dual-chamber pacing for sinusnode dysfunction. N Engl J Med 346(24):1854-1862

77. Ovsyshcher I, Guldal M, Karaoguz R, Katz A, Bondy C (1995) Evaluation of a new rate adaptive ventricular pacemaker controlled by double sensors. Pacing Clin Electrophysiol 18(3 Pt 1):386-390

78. Leung SK, Lau CP, Tang MO (1998) Cardiac output is a sensitive indicator of difference in exercise performance between single and dual sensor pacemakers. Pacing Clin Electrophysiol 21(1 Pt 1):35-41

79. Nägele H, Rödiger W, Castel MA (2008) Rate-responsive pacing in patients with heart failure: long-term results of a randomized study. Europace 10(10):1182-1188

80. Pandey A, Patel KV, Vaduganathan M, Sarma S, Haykowsky MJ, Berry JD et al (2018) Physical activity, fitness, and obesity in heart failure with preserved ejection fraction. JACC Heart Fail 6(12):975-982

81. Fleg JL, Cooper LS, Borlaug BA, Haykowsky MJ, Kraus WE, Levine BD et al (2015) Exercise training as therapy for heart failure: current status and future directions. Circ Heart Fail 8(1):209-220

82. Tucker WJ, Lijauco CC, Hearon CM Jr, Angadi SS, Nelson MD, Sarma S et al (2018) Mechanisms of the improvement in peak $\mathrm{VO}(2)$ with exercise training in heart failure with reduced or preserved ejection fraction. Heart Lung Circ 27(1):9-21

Publisher's Note Springer Nature remains neutral with regard to jurisdictional claims in published maps and institutional affiliations. 